OPEN ACCESS

Edited by:

Matthias Jaeger,

University Hospital of Psychiatry

Zurich, Switzerland

Reviewed by:

Andres Ricardo Schneeberger,

Psychiatrische Dienste

Graubuenden, Switzerland

Niklaus Stulz,

Psychiatric Services Aargau AG,

Switzerland

*Correspondence:

François Borgeat

francois.borgeat@umontreal.ca

Specialty section:

This article was submitted to

Public Mental Health,

a section of the journal

Frontiers in Psychiatry

Received: 27 September 2016 Accepted: 11 January 2017 Published: 31 January 2017

Citation:

Zidani M, Audet J-S, Borgeat F, Aardema F, O'Connor KP and Khazaal Y (2017) Augmentation of Psychotherapy through Alternative

Preconscious Priming: A Case Series Exploring Effects on Residual Symptoms.

Front. Psychiatry 8:8.

doi: 10.3389/fpsyt.2017.00008

\section{Augmentation of Psychotherapy through Alternative Preconscious Priming: A Case Series Exploring Effects on Residual Symptoms}

\author{
Melha Zidani, ${ }^{1,2}$, Jean-Sébastien Audet ${ }^{1,2}$, François Borgeat ${ }^{1,2,3 *}$, Frederick Aardema $^{1,2}$, \\ Kieron Philip O'Connor ${ }^{1,2}$ and Yasser Khazaal',4,5 \\ ${ }^{1}$ Department of Psychiatry, University of Montreal, Montreal, Canada, ${ }^{2}$ Research Center of the Montreal University Institute \\ of Mental Health, Montreal, Canada, ${ }^{3}$ Montreal University Institute of Mental Health, Montreal, Canada, ${ }^{4}$ University of \\ Geneva, Geneva, Switzerland, ${ }^{5}$ Geneva University Hospitals, Geneva, Switzerland
}

The current paper describes a case series using a new strategy for facilitating change based on Augmentation of Psychotherapy through Alternative Preconscious Priming (APAP) (1) in the treatment of eight treatment-resistant patients suffering from social phobia or generalized anxiety disorder. The patients had previously only shown a partial response to cognitive behavioral therapy (CBT) despite good treatment adherence. The patients completed APAP using a computerized program, which consisted of three steps during which alternative, more functional thoughts and beliefs relevant to the idiosyncratic difficulties experienced by the patients were formulated. Subsequently, these formulations were recorded and mixed with masking relaxing music, which the patient listened to in a passive state twice daily for $20 \mathrm{~min}$ for a period of 8 weeks. This case series aimed to assess the effect and acceptability of APAP using quantitative and qualitative measures administered before, after, and 16 weeks' posttreatment. Results showed a reduction in dysfunctional idiosyncratic thoughts reported by most patients, as well as mild improvements in anxiety and important improvements in quality of life. APAP could be a valuable addition to CBT by facilitating or enhancing cognitive and symptom change. Further studies are needed to confirm these promising results.

Keywords: priming, preconcious, social anxiety disorder/social phobia, generalized anxiety disorder, psychotherapy research

\section{INTRODUCTION}

Anxiety disorders, as defined by the fifth edition of the Diagnostic and Statistical Manual of the American Psychiatric Association (2), represent the most frequent mental health problems (3). According to the public health agency of Canada, anxiety disorders currently affect about $12 \%$ of the population and create light to severe impairment (4). Their lifetime prevalence in the general population varies between 16 and 29\% (5). Anxiety disorders also represent a major economic burden for society in terms of direct costs, such as psychiatric or general health services, and indirect costs, such as lost of productivity and unemployment (6). 


\section{Treatment of Anxiety Disorders}

Treatment for anxiety disorder usually consists of antidepressant and cognitive behavioral therapy (CBT) (7). CBT stipulates that cognitions are modifiable through reasoning and that these modifications produce change in emotions and behaviors, which are central in psychiatric disorders (8). CBT is the most studied form of psychotherapy and seems to be the most effective psychotherapy for the treatment of anxiety disorders $(3,9)$. Yet, many patients completing individual or group CBT have residual symptoms and they, or their therapist, still feel that there is room for improvement (10). Old habits of thinking might resist $\mathrm{CBT}$ in those with high anxiety and limited or slow change in psychotherapy can occur even in the presence of a positive patient-therapist alliance and good adherence to treatment (11, 12). One of the factors involved in resistance to change could be that psychotherapists face the very difficult task of helping patients solve long standing emotional and irrational problems with treatment methods that are almost always based on rational and conscious communication.

\section{Preconscious Priming}

People suffering from anxiety disorder have difficulties generating positive scenarios compared to control participants (13), which might account for part of the limited effectiveness of treatments where alternative cognitions or scenarios must be generated rationally by the patient, such as CBT. Priming is a technique by which a stimulus previously presented makes a related but new stimulus more readily available. This should be a potential candidate for helping participants generating or accessing different cognitions. This paradigm has been used mainly in cognitive research, particularly for word recognition. Typically, a word (e.g., cars) is presented, followed by either a word of the same semantic category (e.g., Ferrari) or a different semantic category (e.g., cattle). Results show that the word of the same semantic category is then recognized faster because it has been primed, i.e., is more readily accessible to consciousness (14). If priming can make words more readily available in laboratory word recognition tasks, it could logically produce similar effects in natural settings (15). Hence, the results of priming studies suggest that a repeated activation or priming of cognitions, attitudes, and related emotions can also render a set of positive cognitions and self-statements more readily available to patients.

Priming is postulated to be mostly a preconscious phenomenon (15). Research concerning preconscious processes mainly involves the effect of stimuli presented long enough to be perceived, but not long enough to enter consciousness. For example, Ohman and Soares (16) successfully induced phobic responses by presenting pictures of fearful faces under the threshold of conscious recognition. Masked priming (i.e., unconscious priming) is also more effective than non-masked priming at inducing affective effects (17).

\section{Alternative Preconscious Priming}

The procedure presented in this study is termed APAP for Augmentation of Psychotherapy through Alternative Preconscious Priming. The APAP strategy is based on the notion that priming and masked priming phenomena could render a set of positive cognitions, attitudes, and emotions more available to patients undergoing CBT. A previous randomized controlled study (1) has shown that the addition of APAP to CBT facilitated cognitive change and was associated with increased positive cognitions and decreased negative cognition in social phobia. This study also suggested that patients with important residual anxiety following CBT could benefit more from APAP than patients with less residual anxiety. A recent case report also demonstrated the effectiveness of APAP in a patient with severe social phobia (18).

\section{Aims}

The current case series adds to the previous randomized controlled trial in two ways: first, the subjects were treatment-resistant social anxiety disorder (SAD) or generalized anxiety disorder (GAD) patients still showing important residual symptoms and, second, a new computerized program available through the internet and linking all the steps of the procedure was employed. The following questions were explored: Were residual symptoms of SAD or GAD improved by the addition of APAP? Was the use of the APAP program available through internet viewed as user friendly? Was the possibility of individual work at home with the possibility of relying on a therapist through internet judged positively?

\section{METHOD}

\section{Subjects}

Nine SAD or GAD patients were recruited at a specialized anxiety clinic. This clinic receives patients deemed treatment resistant after two unsuccessful treatment attempts, either with drugs or psychotherapy, but more frequently following two unsuccessful pharmacological attempts. Patients were referred to the clinic by their physician and received individual or group CBT. The format, duration, and intensity of the treatment were personalized to the patient. Participants were referred to the study by their therapist (psychologist or psychiatrist) based on important residual symptoms.

Of the nine participants entering treatment, one participant desisted because of a lengthy stay outside of the county, leaving eight completers (age range: 22-71 years old; five women; four $\mathrm{SAD}$, and four GAD). Diagnostics were obtained through clinical judgment of professionals and were confirmed through previous diagnostics.

Inclusion criteria were (1) being over the age of 18 years old; (2) having a primary diagnostic of SAD or GAD; (3) presenting residual symptoms after CBT despite good treatment adherence; and (4) no evidence of substance or alcohol abuse within the past 6 months. Participants were excluded if they had (1) a current primary mood disorder, except for premorbid dysthymia or (2) a history of psychotic disorder or eating disorder.

Participants gave consent prior to the beginning of the study and were assessed by the first and third author at baseline. Participants' age and diagnostics are presented in Table 1. All names have been changed to preserve anonymity. 
TABLE 1 | Participants' age and diagnostics.

\begin{tabular}{lll}
\hline Participants & Age & Diagnostics \\
\hline Caroline & 34 & SAD \\
Natalia & 22 & GAD \\
Sharon & 39 & GAD, OCD, and SAD \\
Isabelle & 31 & SAD, dysthymia, and subclinical OCD \\
Geneviève & 28 & GAD, obsessional personality traits and \\
& & dependant personality traits \\
Pierre & 71 & GAD, slight premorbid prefrontal perturbation \\
Claude & 44 & SAD \\
Haroun & 32 & SAD, dysthymia; ADD \\
\hline Mean & 37.63 & -
\end{tabular}

$G A D$, generalized anxiety disorder; $S A D$, social anxiety disorder; $O C D$, obsessivecompulsive disorder; $A D D$, attention-deficit disorder.

\section{Measures}

\section{Beck Anxiety Inventory (BAI)}

The BAI (19) is a 21-item questionnaire measuring the intensity of anxiety symptoms in the past week. As with the English version, the French version present a good internal consistency $(\alpha=0.84)$ and a good test-retest fidelity $(r=0.63)(20)$.

\section{Hamilton Anxiety Rating Scale (HARS)}

The HARS (21) measures state anxiety using 14 items. These items cover the following dimensions: psychic anxiety, somatization, cognitive impairments, sleep difficulties, and depressive mood. The interrater reliability is excellent $(r=0.89)(21)$ and convergent validity with other measures of anxiety is good $(r=0.51)$. The French validation was used in this study (22).

\section{Quality of Life Systematic Inventory (QLSI)}

The QLSI (23) measures participant's quality of life by measuring their capacity to reach their personal goals in nine different life spheres. The QLSI presents a good test-retest reliability $(r=0.84)$ and good divergent validity with social desirability ( $r$ between 0.11 and -0.13 ) (23).

\section{Idiosyncratic Measure of Convictions in Thoughts}

This measure was designed specifically for the study and was inspired by the postulate of cognitive theory according to which change in cognition brings change in emotions and behaviors (8). Many other studies have used this methodology $(24,25)$ and this type of measure has been previously validated (26). The idiosyncratic measure asks participants to name the thoughts that would be targeted by APAP and to rate the degree of conviction in each thought in percentage. Thoughts targeted by APAP were decided by the patient and the therapist (see Procedure), but the ratings were provided by the patients independently of therapist. The mean of the ratings was used as a total score to effectively compare participants.

\section{Procedure}

The study was approved by the local ethics and research committees. Participants with residual symptoms still causing disturbances were approached at the end of their CBT and invited to participate in APAP. Participants were informed that APAP could help to free them from a cognitive rut by making different cognitions more available to them. If the participants agreed to participate, individual sessions with FB and the participant's therapist were organized to explain the procedure. The participants received at least two sessions face to face explaining APAP, its rationale, and how the procedure could be adapted to their situation. Afterward, participants had the option of continuing the therapeutic work by themselves over the internet through the APAP website ${ }^{1}$ or by doing it partly or totally face to face with the therapist using the web interface together. Information was exchanged via the APAP website's interface for patients choosing to work from the internet to help specify the targets of change. The therapeutic work proceeded as follows: (1) recap on difficulties regarding change in cognition and inner discourse and explanation of APAP rationale (this step occurred in person); (2) exploring the residual problematic cognitions and related emotions and mental imagery (case formulation with the patient and her/his therapist using the APAP website); (3) making a list of plausible alternative and desired personal cognitions (formulated by the patient with the input of her/his therapist using the APAP website); and (4) explaining the listening modalities, which were: passive, effortless listening, and at least 20-30 min a day for 8 weeks. The listening setting could be during a relaxing moment, for instance at bedtime, but could also be used before or during stressful situations.

The list of plausible alternatives created by the patient were mixed with relaxing music chosen by the patient. The music was 20-30 dB stronger than the plausible alternatives to actively mask it. Participants were given the option to change the music using the APAP website to prevent boredom and increase motivation. They were also required to hold a diary monitoring their adherence to the treatment. Participants were contacted weekly by the first author to verify their adherence and to respond to any queries. Questions concerning the website as well as information about life event of participants were collected during the weekly contacts and at end point ( 8 and 24 weeks). Also, 4-6 weeks after the beginning of the procedure, patients were evaluated and changes were made to the plausible alternatives, if judged necessary. The trial ended after 8 weeks and further follow-up was made at 24 weeks (16 weeks posttreatment).

\section{RESULTS}

\section{Change in Dysfunctional Thoughts and Anxiety Symptoms}

Table 2 presents the mean degree of conviction in the different dysfunctional beliefs held by each APAP participants before the beginning of the procedure and at 24 weeks. Substantial decrease from pre to 16 weeks posttreatment in the mean conviction were observed and only one participant (Sharon) failed to improve

\footnotetext{
${ }^{1}$ The program is available in French freely to psychotherapist upon request to the corresponding author.
} 
TABLE 2 | Conviction in dysfunctional thoughts pre-APAP and at 24 weeks.

\begin{tabular}{|c|c|c|c|c|}
\hline Participants & Triggers of anxiety & Dysfunctional thoughts & $\begin{array}{c}\text { Conviction in } \\
\text { dysfunctional thoughts } \\
\text { pre-APAP (\%) }\end{array}$ & $\begin{array}{c}\text { Conviction in } \\
\text { dysfunctional thoughts } \\
\text { at } 24 \text { weeks }(\%)\end{array}$ \\
\hline Caroline & Talking in front of groups & I express myself badly; my voice sound weird; I feel overwhelmed & 96.7 & 31.7 \\
\hline Natalia & $\begin{array}{l}\text { Fear of failure, } \\
\text { particularly in school }\end{array}$ & $\begin{array}{l}\text { I have difficulties taking decisions; I have uncertainties about the } \\
\text { future; I won't be able }\end{array}$ & 82.1 & 21.4 \\
\hline Sharon & $\begin{array}{l}\text { Feeling judged when } \\
\text { meeting people }\end{array}$ & $\begin{array}{l}\text { I'm afraid people will be angry at me; I'm afraid people will say bad } \\
\text { things about me; I'm afraid people are going to laugh at me }\end{array}$ & 90 & 90 \\
\hline Isabelle & $\begin{array}{l}\text { Cannot manage anxiety } \\
\text { when starting a new job }\end{array}$ & $\begin{array}{l}\text { I'll always be anxious; I won't adapt, I'll fail again; others will think } \\
\text { I'm incompetent }\end{array}$ & 83.3 & 36.3 \\
\hline Geneviève & $\begin{array}{l}\text { Anticipation about } \\
\text { returning to work }\end{array}$ & $\begin{array}{l}\text { I'm concerned about going back to work; l'll be sick; I won't be } \\
\text { able to do anything }\end{array}$ & 98.9 & 77.8 \\
\hline Pierre & Anxiety about parking & $\begin{array}{l}\text { I won't find a parking spot when l'll get back; I won't know where } \\
\text { to park; my car will get vandalized }\end{array}$ & 66 & 17 \\
\hline Claude & $\begin{array}{l}\text { Feeling invaded in social } \\
\text { situations }\end{array}$ & I feel invaded; I won't control my life; I express myself badly & 88.6 & 68.6 \\
\hline Haroun & $\begin{array}{l}\text { Anticipation of anxiety } \\
\text { during phone calls }\end{array}$ & $\begin{array}{l}\text { I'm unable to express my objectives; I'm afraid of reaction; I'm } \\
\text { afraid of making a phone call }\end{array}$ & 64 & 44 \\
\hline Mean & - & - & 83.7 & 48.4 \\
\hline
\end{tabular}

TABLE 3 | Change in quality of life and anxiety symptoms during APAP.

\begin{tabular}{|c|c|c|c|c|c|c|c|c|}
\hline & \multicolumn{2}{|c|}{ QLSI } & \multicolumn{3}{|c|}{ BAI } & \multicolumn{3}{|c|}{ HARS } \\
\hline & Baseline & 24 weeks & Baseline & 8 weeks & 24 weeks & Baseline & 8 weeks & 24 weeks \\
\hline Caroline & 3 & 69 & 33 & 9 & 14 & 14 & 20 & 18 \\
\hline Natalia & 3 & 71 & 14 & 11 & 5 & 17 & 11 & 7 \\
\hline Sharon & 2 & 13 & 42 & 36 & 41 & 46 & 37 & 35 \\
\hline Isabelle & 3 & 13 & 10 & 5 & 7 & 18 & 10 & 10 \\
\hline Geneviève & 2 & 13 & 28 & 20 & 21 & 30 & 28 & 25 \\
\hline Pierre & 2 & 48 & 35 & 22 & 20 & 14 & 24 & 25 \\
\hline Claude & 3 & 13 & 9 & 16 & 20 & 30 & 28 & 21 \\
\hline Haroun & 2 & 13 & 13 & 36 & 25 & 35 & 23 & 26 \\
\hline Mean & 2.5 & 31.6 & 23 & 19.4 & 19.1 & 26 & 22.63 & 20.9 \\
\hline
\end{tabular}

QLSI, Quality of Life Systematic Inventory; BAI, Beck Anxiety Inventory; HARS, Hamilton Anxiety Rating Scale.

in regard to cognitions, but remained stable. All participants showed an increase in quality of life as well as an overall decrease in anxiety symptoms (see Table 3 ). Decrease in anxiety symptoms was modest, with some participants greatly decreasing (e.g., Caroline on the BAI) and others showing increase in symptoms (e.g., Pierre on the HARS). No participants showed an increase on both the BAI and the HARS suggesting that there was at least some improvement with all participants. There was also no relapse during follow-up.

\section{Patient's Report and Their Perception of APAP and Its Website}

Participants reported further gains that could be attributable to APAP. Sharon and Geneviève started doing some volunteer work. Isabelle returned to work while Sharon and Genevieve joined a return to work group after APAP. Claude decided to go back to work for the first time in 6 years and started a traineeship for people reintegrating the market place during the follow-up. Caroline made new friends and kept regular contact with them, as well as exposing her paintings. Finally, Haroun started reusing the phone.

There were also events not related to APAP that could have negatively impacted participants. Natalia moved, Pierre had some health problems, and his wife was hospitalized just before the end of the eighth week (he went on to have worries about health which were not targeted during his APAP trial) and Haroun was accused of sexual harassment.

Participants' testimony revealed that they greatly appreciated the possibility of working autonomously with APAP while being able to rely on their therapist, if needed. They appreciated being listened to when they felt the need to change their therapeutic 
target and they underlined the importance of a fluid program that allows to make such changes according to the patient's needs.

\section{DISCUSSION}

The present study sought to investigate the effectiveness of an augmentation of psychotherapy through alternative preconscious priming (APAP) intervention following CBT in treatment-resistant patients with residual symptoms. The procedure was supported by a patient-clinician collaborative website specifically designed for this purpose. Results showed improvement in targeted cognitions, quality of life, and anxiety symptoms during APAP that were maintained at follow-up, indicating that APAP could be used to help diminish residual symptoms of SAD and GAD following CBT. The users also positively appraised the procedure and the website. This study suggests that APAP could be a useful addition to CBT, particularly for those affected by resistant problematic cognition and internal discourse. Conceptually, APAP rationale is similar to CBT as it aims to change problematic cognitions postulated to be related to negative emotion and behaviors. To our knowledge, no other study has been reported using a rationale of preconscious priming or using repeated preconscious listening in the context of psychotherapy augmentation.

As previously mentioned by Tulving and Schacter (15), priming can have practical therapeutic uses. Change in cognitions targeted by APAP suggests sound internal validity of the intervention, APAP being the only intervention received by participants which targeted these thoughts. The results replicate the change in cognition found in a previous validation of APAP (1). While the reduction in anxiety was modest, the improvement in quality of life was substantial for some participants and gains in functioning were achieved by all participants and maintained at follow-up. This suggest that 8 weeks of passive repeated preconscious listening could have lasting effects beyond the use of a simple listening period. Results also suggest that comorbidities (particularly OCD and personality traits/disorder) or life events could diminish the effectiveness of APAP, as they do with any therapy. Yet even those with comorbidities or encountering adverse life events improved in some way.

Like APAP, other internet based treatments have also shown effectiveness (27), even compared with the usual treatments (28). These results are encouraging for internet intervention and suggest that some people might respond better when the setting is different then traditional psychotherapy.

Preconscious processes are also implicated in other anxiety disorders. People with obsessive-compulsive disorder show preconscious learning difficulties using a procedural task compared to healthy controls. ${ }^{2}$ Change in preconscious processes (in this case, attention processes) can effectively reduce the risk of developing subsequent posttraumatic stress disorder (29). This tends

${ }^{2}$ Dulude G, Bédard M-A, O'Connor K, Audet J-S. Over facilitation of unadapted cognitive processes in obsessive compulsive disorder as assessed with the computerized mirror pointing task. J Psychiatr Res (In revision). to show the importance of preconscious processes in anxiety disorders as an area to investigate, particularly for those who are treatment resistant.

\section{Limits}

In this case series, it is hard to distinguish the gains from APAP from the influence of other factors, for example, the residual effect of the participants' previous CBT. However, APAP has been previously validated as an effective procedure beyond residual effect of CBT and bogus priming (1). The small sample size and the nature of the study prevent us from generalizing the observation reported. A future replication should thus use a larger sample. The reliance of self-report assessment prevents us from distinguishing theses results from participants' biases, since they were not blind to the study hypothesis. Future studies should address this issue.

\section{Strengths and Clinical Implications}

This is the first time APAP has been used to treat GAD, the previous study focusing only on SAD (1), implying that APAP can be used to target various anxiety symptoms. This was also the first time that APAP was delivered over the internet, which was appreciated by the participants and allowed flexibility in the program. The previous utilization of APAP necessitated the use of a recording studio, limiting the capacity to adapt APAP to individual needs over time.

\section{Future Recommendations}

Future studies could include randomized controlled trial of APAP with a larger sample size, which would also aim to understand which clinical characteristic predicts meaningful response to APAP. Other psychiatry disorders presenting problematic internal discourse could potentially benefit from a similar procedure. APAP could also be applied in other formats (e.g., as a self-help procedure or combined with medication).

\section{CONCLUSION}

Alternative Preconscious Priming could be a new and useful strategy to facilitate cognitive change and augment the effects of psychotherapy. In the present study, it helped to diminish participants' anxiety and improved their quality of life. Patients presenting comorbid OCD and personality disorder might not benefit from APAP as much as other patients. The use of a website was judged appropriate to facilitate access and autonomy, but improvements are still needed to increase program friendliness. Further studies, especially controlled studies, are warranted to assess APAP usefulness and its possible applications.

\section{ETHICS STATEMENT}

The study was approved by the comite d'éthique de la recherche de l'institut universitaire en santé mentale de Montréal. This ethics committee has been dissolved due to recent changes in the administrative structure. It is now called: comité d'éthique de la recherche du centre intégré universitaire de santé et des services 
sociaux de l'est-de-Montréal. Participants were approached at the end of their psychotherapy and they were invited to participate in the current study. They were given the consent form and were told to read it thoroughly before agreeing. The research team answered any question concerning the consent form, and all was done to ensure that participants understood that they were free to disengage from the study at any points and that there would be no consequences to their disengagement.

\section{REFERENCES}

1. Borgeat F, O'Connor K, Amado D, St-Pierre-Delorme M-E. Psychotherapy augmentation through preconscious priming. Front Psychiatry (2013) 4:15. doi:10.3389/fpsyt.2013.00015

2. American Psychiatric Association. Diagnostic and Statistical Manual of Mental Disorders: DSM-5. 5th ed. Arlington, VA: American Psychiatric Association (2013). 947 p.

3. Bernier JP, Simard I. Mise à jour dans le traitement des troubles anxieux. Pharmactuel (2007) 40(4):204-17.

4. Canadian Public Health Agency. Rapport sur les maladies mentales au Canada. (2002). Available from: http://www.phac-aspc.gc.ca/publicat/miic-mmac/ chap_4-fra.php\#tphp

5. Kessler RC, Aguilar-Gaxiola S, Alonso J, Chatterji S, Lee S, Ormel J, et al. The global burden of mental disorders: an update from the WHO World Mental Health (WMH) surveys. Epidemiol Psichiatr Soc (2009) 18(1):23-33.

6. Canadian Psychiatrist Association. Clinical pratice guide. Can J Psychiatry (2006) 51(8 Suppl 2):9S-91S.

7. American Psychiatric Association. Practice Guideline for the Treatment of Patients with Anxiety Disorders. Arlington, VA: American Psychiatric Association (2007).

8. Beck AT. Cognitive Therapy and the Emotional Disorders. New York, NY: Meridian (1979). 368 p.

9. Hofmann SG, Smits JA. Cognitive-behavioral therapy for adult anxiety disorders: a meta-analysis of randomized placebo-controlled trials. J Clin Psychiatry (2008) 69(4):621-32. doi:10.4088/JCP.v69n0415

10. Garakani A, Mathew SJ, Charney DS. Neurobiology of anxiety disorders and implications for treatment. Mt Sinai J Med (2006) 73(7):941-9.

11. Castonguay LG. Psychotherapy outcome: an issue worth re-revisiting 50 years later. Psychotherapy (2013) 50(1):52-67. doi:10.1037/a0030898

12. Cottraux J. Les thérapies comportementales et cognitives. Médecine (2006) 10(6):451-5. doi:10.1684/med.2006.0046

13. Morina N, Deeprose C, Pusowski C, Schmid M, Holmes EA. Prospective mental imagery in patients with major depressive disorder or anxiety disorders. J Anx Dis (2011) 25:1032-7. doi:10.1016/j.janxdis.2011.06.012

14. Tulving E, Schacter DL, Stark HA. Priming effects in word-fragment completion are independent of recognition memory. J Exp Psychol Learn Mem Cogn (1982) 8(4):336-42. doi:10.1037/0278-7393.8.4.336

15. Tulving E, Schacter DL. Priming and human memory systems. Science (1990) 247:301-5. doi:10.1126/science.2296719

16. Ohman A and Soares JJ. "Unconscious anxiety": phobic responses to masked stimuli. J Abnorm Psychol (1994) 103:231-40.

17. Masson MEJ, Bodner GE. A retrospecive view of masked priming: toward a unified account of masked and long-term repetition priming. In: Kinoshita S, Lupker SJ, editors. Masked Priming: The State of the Art. New York: Psychology Press (2003). p. 57-94.

18. Zidani M, Borgeat F, O'Connor K, Aardema F. Augmentation of psychotherapy by preconscious priming (APAP): a case study [augmentation de la psychothérapie par amorçage préconscien (APAP): étude d'un cas]. Journal

\section{AUTHOR CONTRIBUTIONS}

$\mathrm{MZ}, \mathrm{FB}, \mathrm{FA}$, and YK contributed to the design of the work. MZ and FB collected the data. MZ analyzed the data. MZ, J-SA, FB, $\mathrm{FA}, \mathrm{KO}$, and $\mathrm{YK}$ participated in the interpretation of the data. J-SA drafted the manuscript. MZ, FB, FA, KO, and YK revised the manuscript critically. All the authors approved the final version of the manuscript.

de thérapie comportementale et cognitive (2015) 25:85-92. doi:10.1016/ j.jtcc.2015.06.001

19. Beck AT, Epstein N, Brown G, Steer RA. An inventory for measuring clinical anxiety: psychometric properties. J Consult Clin Psychol (1988) 56(6):893-7. doi:10.1037/0022-006X.56.6.893

20. Freeston MH, Ladouceur R, Thibodeau N, Gagnon F, Rheaume J. [The Beck Anxiety Inventory. Psychometric properties of a French translation]. Encephale (1994) 20(1):47-55.

21. Hamilton M. The assessment of anxiety states by rating. Br J Med Psychol (1959) 32:50-5. doi:10.1111/j.2044-8341.1959.tb00467.x

22. Von Frenckel R. Reparamétrisation et analyse de léchelle d'anxiété de M. Hamilton. Psychologie Médicale (1980) 12(13):2769-72.

23. Duquette RL, Dupuis G, Perrault J. A new approach for quality of life assessment in cardiac patients: rationale and validation of the Quality of Life Systemic Inventory. Can J Cardiol (1994) 10(1):106-12.

24. Aardema F, O'Connor K, Delorme ME, Audet JS. The inference-based approach (IBA) to the treatment of obsessive-compulsive disorder: an open trial across symptom subtypes and treatment-resistant cases. Clin Psychol Psychother (2016). doi:10.1002/cpp.2024

25. O'Connor K, Aardema F, Bouthillier D, Fournier S, Guay S, Robillard S, et al. Evaluation of an inference-based approach to treating obsessive-compulsive disorder. CogBeha Ther (2005) 34(3):148-63. doi:10.1080/16506070510041211

26. Polman A, Bouman TK, van Geert PLC, de Jong PJ, den Boer JA. Dysfunctional beliefs in the process of change of cognitive treatment in obsessive compulsive checkers. Clin Psychol Psychother (2010) 18(3):256-73. doi:10.1002/cpp.707

27. Twomey C, O’Reilly G, Byrne M, Bury M, White A, Kissane S, et al. A randomized controlled trial of the computerized CBT programme, MoodGYM, for public mental health service users waiting for interventions. Br J Clin Psychol (2014) 53:433-50. doi:10.1111/bjc.12055

28. Strid C, Andersson C, Forsell Y, Öjehagen A, Lundh L-G. Internet based cognitive behaviour therapy and physical exercise - effects studied by automated telephone assessment in mental ill-health patients, a randomized controlled trial. Br J Clin Psychol (2016) 55:414-28. doi:10.1111/bjc.12111

29. Wald I, Fruchter E, Stolin E, Dagan D, Bliese PD, Quartana PJ, et al. Selective prevention of combat related post-traumatic stress disorder using attention bias modification training: a randomized controlled trial. Psychol Med (2016) 46:2627-36. doi:10.1017/S0033291716000945

Conflict of Interest Statement: The authors declare that the research was conducted in the absence of any commercial or financial relationships that could be construed as a potential conflict of interest.

Copyright (C) 2017 Zidani, Audet, Borgeat, Aardema, O’Connor and Khazaal. This is an open-access article distributed under the terms of the Creative Commons Attribution License (CC BY). The use, distribution or reproduction in other forums is permitted, provided the original author(s) or licensor are credited and that the original publication in this journal is cited, in accordance with accepted academic practice. No use, distribution or reproduction is permitted which does not comply with these terms. 